\title{
Outcome of Patients with Non-Small Cell Lung Cancer and Brain Metastases: Egyptian Experience
}

\author{
Salah Elmesidy, Hussam Zawam, Asmaa Hassan, Mohamed Abol-Kasem, Radwa Fawzy, \\ Mahmoud Abdelsalam
}
Department of Clinical Oncology, Kasr Al-Ainy Center of Clinical Oncology and Nuclear Medicine (NEMROCK), Kasr Al-Ainy School of Medicine, Cairo University, Cairo, Egypt.

Background: Lung cancer remains the most common primary tumor responsible for brain-metastases (BM) leading to $40 \%-50 \%$ of cases. BM from Non-Small Cell Lung Cancer (NSCLC) is associated with poor prognosis.

Aim: This study aimed to analyze risk factors and treatment outcome of patients with NSCLC who developed BM, and also to identify which subgroup of these patients is associated with better survival outcome.

Methods: This retrospective study included data of 714 patients with NSCLC presented to an Egyptian cancer center during the period between January 2006 and December 2012. Of them, 132 patients had clinical evidence of BM.

Results: The median time to development of BM (TTBM) was 6 months. Factors associated with longer TTBM were better Eastern Cooperative Oncology Group (ECOG) performance status score $1-2(p=0.004)$, early stages at presentation (stage I-II) $(p<0.0001)$, and administration of chemotherapy $(p<0.0001)$. Median OS (OS) from the time of development of BM was 5 months. Factors associated with longer OS were better performance status (ECOG 1 - 2) at development of BM $(p<0.0001)$, controlled lung primary $(p<0.0001)$, absence of extracranial metastases $(p=0.019)$, the use of chemotherapy after development of BM $(p<0.0001)$ and whole brain irradiation $(p=0.001)$. Controlled lung primary and administration of chemotherapy were independent favorable prognostic factors associated with higher OS ( $p=0.006$ and 0.02 , respectively).

Conclusion: After the development of BM; NSCLC patients with good performance status, controlled lung primary and without extracranial metastases have a better outcome.

Key words: Non-small cell lung cancer, brain metastases, whole brain radiation, Egypt.

Corresponding Author: Hussam Zawam, M.D. Department of Clinical Oncology, Kasr Al-Ainy Center of Clinical Oncology and Nuclear Medicine (NEMROCK), Kasr Al-Ainy School of Medicine, Cairo University; Cairo 11562, Egypt, Egypt, E-mail: huszawam@kasralainy.edu.eg

Received: 28-January-2017, Revised: 8-February-2017, Accepted: 13-February-2017

\section{INTRODUCTION}

Lung cancer remains the most common lethal malignancy worldwide. Moreover, it is the leading cause of cancer mortality in both men and women, being responsible for $26-27 \%$ of all cancer mortality ${ }^{1}$.

Data collected for the year 2008, from the Middle East and Africa, revealed that about 16,600 lung cancer cases were newly diagnosed in the Arab countries. The majority of cases were from North Africa. The highest incidences were from Egypt (20.6\%) and Morocco $(20.1 \%)^{2}$. Noteworthy, more than 15,000 deaths related to lung cancer were estimated in the Arab populations, and the highest mortality rates were also from Egypt (20.7\%), then Morocco $(20.4 \%)^{3}$.

Metastases to the brain occur in as many as $30 \%$ of patients with systemic cancer. ${ }^{4}$ The most common primary tumors responsible for brain metastases (BM) are lung cancer (making up approximately $40 \%$ to $50 \%$ of cases), breast cancer $(15 \%)$ and melanoma $(10 \%)^{5}$. The incidence of BM in patients with NSCLC is highly variable among different series. In one review, the percentage varied from $18 \%$ to $64 \%^{6}$. Autopsy series have shown an incidence of about $26 \%{ }^{7}$.

The routine use of magnetic resonance imaging (MRI) for NSCLC staging makes BM a significant problem. Also the availability of more effective systemic therapy for NSCLC has made the brain a frequent site of relapse ${ }^{8}$.

In general, BM is associated with a poor prognosis. Historically, treatment of BM included the combination of whole-brain irradiation (WBI) and corticosteroids?. More recently, there has been a shift toward more aggressive local therapies for patients with solitary or oligo-metastatic brain lesions ${ }^{10}$.

Some evidence suggest that BM respond to chemotherapy at a rate similar to that seen with the primary tumour and systemic disease ${ }^{11}$. A randomized trial of patients with NSCLC and BM demonstrated that survival rates are similar for cases treated with initial chemotherapy and delayed WBI and other cases treated with immediate $\mathrm{WBI}^{12}$. In a retrospective 
review, patients with BM from NSCLC who remained stable and were included in chemotherapy trials, had similar survival to that of patients with advanced disease without $\mathrm{BM}^{13}$. Targeted agents in patients with BM from NSCLC remains an area of ongoing clinical trials ${ }^{14,15}$. However, those reports used mainly selected groups of patients with young age, good neurologic function and performance status, with small number of lesions and controlled primary cancer. Therefore the results can not be generalized.

Identifying NSCLC patients with BM who have a good prognosis may limit the number of patients subjected to withdrawal of systemic treatment because of the perception of poor prognosis.

In this study, we aimed at describing the risk factors and treatment outcome of NSCLC with BM and at identifying a subgroup of patients who might have favorable outcome and thus could benefit from more aggressive therapies.

\section{PATIENTS AND METHODS}

This retrospective study included all NSCLC patients presented to Kasr Al-Ainy Center of Clinical Oncology and Nuclear Medicine (NEMROCK) during the period from January 2006 to December 2012. The inclusion criterion was NSCLC with $\mathrm{BM}$ either at initial presentation or at any time during follow up.

A total of 714 patients were reviewed, of which 112 were excluded due to either incomplete data or not fulfilling the inclusion criteria. Of the remaining 602 patients, $132(21.9 \%)$ had BM and were included in the study. The files of the patients were reviewed for epidemiological data, clinico-pathological data and treatment outcome.

Data were described in terms of mean \pm standard deviation, median and range, or frequencies and percentages. Time to BM (TTBM) was determined from the date of diagnosis of lung cancer to the date of diagnosis of BM. While, progression free survival was determined as the time from date of diagnosis of BM to the date of progression of either the lung primary or the BM. Besides, the overall survival (OS) after BM was defined as time from date of diagnosis of BM to date of death from any cause or to the date of last contact for surviving patients.

Survival analysis was done using the Kaplan-Meier method with comparison using the Log Rank test. P-values less than 0.05 were considered significant. Data analysis was performed using the Statistical Package for the Social Science (SPSS Inc., Chicago, IL, USA) version 17 for Microsoft Windows.

\section{RESULTS}

The majority of patients were males $(87.9 \%)$, with a median age of 56 years (range from 30 to 73 years). Of the 132 patients enrolled in this work, 65 patients (49.2\%) had BM at initial presentation. Other features of patients at presentation are shown in Table 1.

The presentation and treatment of BM are summarized in Table 2. Headache was a major complaint in $42 \%$ of patients. About half of the patients were diagnosed by CT and the other half by MRI. The majority of patients had multiple BM, whereas the cerebral hemispheres were the most common sites.

Of the 42 patients, who had single BM; 17 patients had only BM without metastases in other sites, 11 underwent metastatectomy and 3 received stereotactic boost after WBI. Noteworthy, WBI was given in 129 patients while the remaining 3 patients didn't receive it due to poor general condition.

With the exclusion of 65 patients who had BM at initial presentation, the median TTBM for the other 67 patients ranged from 2 to 22 months with a median of 6 months (95\% CI: $5.3-6.7)$.

In a univariate analysis; factors associated with longer TTBM were; good Eastern Cooperative Oncology Group (ECOG) performance status score $1-2$ at time of initial diagnosis $(P=0.004)$, early stage at presentation (stage 1-2) $(P<0.0001)$ and the use of chemotherapy $(P<0.0001)$ as shown in Table 3 .

While in multivariate Cox regression analysis; only early stage (I-II) at presentation was statistically significant $(P=0.001)$ (Figure 1).

Age group, sex, pathological subtypes, surgical resection of the lung primary, and radiotherapy applied to the lung primary" had no impact on TTBM.

The median progression free survival was found to be 4.5 months (95\% CI: $3.98-5.02)$, which was close to the OS of 5 months (95\% CI: $4.4-5.6)$. In a univariate analysis; factors associated with longer OS were; good performance status (ECOG 1-2) at development of BM, controlled lung primary, absence of extracranial metastases, the use of chemotherapy after development of BM and WBI (illustrated in Table 4). In multivariate Cox regression analysis, only controlled lung primary and administration of chemotherapy after development of BM were statistically significant $(P=0.006$ and 0.02 , respectively). Other analyzed factors including; age group, gender, pathological subtypes, presentation by coma, number of BM and metastatectomy operation, were not statistically significant. 
Table 1: Patients' characteristics at presentation.

\begin{tabular}{lcc}
\hline \multicolumn{4}{l}{ No. } & \% \\
\hline Gender & & \\
\hline Males & 116 & 87.9 \\
\hline Females & 16 & 12.1 \\
\hline
\end{tabular}

\begin{tabular}{ccc}
\hline Age (years) & & \\
\hline$<60$ & 88 & 66.7 \\
\hline$\geq 60$ & 44 & 33.3 \\
\hline Smoking history & & \\
\hline Yes & 83 & 62.9 \\
\hline No & 49 & 37.1 \\
\hline ECOG PS & & \\
\hline 1 & 39 & 29.6 \\
\hline 2 & 45 & 34.1 \\
\hline 3 & 28 & 21.2 \\
\hline 4 & 9 & 6.8 \\
\hline Unknown & 11 & 8.3 \\
\hline
\end{tabular}

\begin{tabular}{lll}
\hline Clinical manifestations & & \\
\hline Cough & 72 & 54.5 \\
\hline Dyspnea & 20 & 15.2 \\
\hline Chest pain & 35 & 26.5 \\
\hline Haemoptysis & 12 & 17.9 \\
\hline Weight loss & 23 & 17.4 \\
\hline
\end{tabular}

Side of primary

\begin{tabular}{llc}
\hline \multicolumn{1}{l}{ Right lung } & 62 & 47 \\
\hline Left lung & 70 & 53 \\
\hline Pathology & & \\
\hline Adenocarcinoma & 68 & 51.5 \\
\hline Squamous & 34 & 25.8 \\
\hline Large cell & 19 & 14.4 \\
\hline Undifferentiated & 11 & 8.3 \\
\hline Grade & & \\
\hline I & 5 & 3.8 \\
\hline II & 64 & 48.5 \\
\hline III & 63 & 47.7 \\
\hline Site of distant metastases & & \\
\hline None & 56 & 42.5 \\
\hline Brain only & 39 & 29.5 \\
\hline Brain and other sites & 26 & 19.7 \\
\hline Other sites only & 11 & 8.3 \\
\hline Stage & & \\
\hline I & 6 & 4.6 \\
\hline II & 12 & 9.1 \\
\hline III & 36 & 27.3 \\
\hline IV & 76 & 57.6 \\
\hline Missing & 2 & 1.5 \\
\hline ECOG: Easn Coopar & & \\
\hline
\end{tabular}

ECOG: Eastern Cooperative Oncology Group
Table 2: Presentation and treatment of brain metastases

\begin{tabular}{lcc}
\hline & No. & \% \\
\hline Method of diagnosis & & \\
\hline CT & 63 & 47.7 \\
\hline MRI & 69 & 52.3 \\
\hline
\end{tabular}

Number of BM

\begin{tabular}{lcc}
\hline Multiple & 90 & 68.2 \\
\cline { 2 - 3 } Single & 42 & 31.8 \\
\hline Site of BM & & \\
\hline Cerebral & 112 & 84.8 \\
\hline Cerebellar & 41 & 31.1 \\
\hline Brain stem & 3 & 2.3 \\
\hline
\end{tabular}

Clinical manifestations of BM

\begin{tabular}{lcc}
\hline Headache & 55 & 41.7 \\
\hline Vomiting & 39 & 29.5 \\
\hline Convulsions & 14 & 10.6 \\
\hline Coma & 24 & 18.2 \\
\hline Motor & 41 & 31.1 \\
\hline Sensory & 9 & 6.8 \\
\hline Autonomic & 9 & 6.8 \\
\hline
\end{tabular}

\begin{tabular}{lcc}
\hline ECOG PS at presentation & & \\
\hline 1 & 29 & 22 \\
\hline 2 & 32 & 24.2 \\
\hline 3 & 42 & 31.8 \\
\hline 4 & 17 & 12.9 \\
\hline Unknown & 12 & 9.1 \\
\hline
\end{tabular}

Status of the lung $1^{\text {ry }}$ at presentation

\begin{tabular}{|c|c|c|}
\hline Controlled & 36 & 27.3 \\
\hline Uncontrolled & 96 & 72.7 \\
\hline
\end{tabular}

Surgical resection of the lung $1^{\text {ry }}$

\begin{tabular}{ccc}
\hline Yes & 10 & 7.6 \\
\hline No & 122 & 92.4 \\
\hline Metastatectomy $^{* * *}$ & & \\
\hline Yes & 11 & 26.2 \\
\hline No & 31 & 73.8 \\
\hline
\end{tabular}

Chemotherapy before BM diagnosis $^{\text {****}}$

\begin{tabular}{lll} 
Yes & 57 & 85.1 \\
\hline No & 10 & 14.9 \\
\hline
\end{tabular}

Chemotherapy after BM diagnosis

\begin{tabular}{lcc}
\hline Yes & 44 & 33.3 \\
\hline No & 88 & 66.7 \\
\hline Radiotherapy to the lung primary & & \\
\hline Yes & 36 & 72.7 \\
\hline No & 96 & 27.3 \\
\hline Whole brain irradiation & & \\
\hline Yes & 129 & 97.7 \\
\hline No & 3 & 2.3 \\
\hline Stereotactic boost ${ }^{\text {** }}$ & & \\
\hline Yes & 3 & 7.1 \\
\hline No & 39 & 92.9 \\
\hline
\end{tabular}

*The uncontrolled group contains 65 patients who presented initially with $\mathrm{BM} ;{ }^{* *}$ Results are analyzed for patients with single $\mathrm{BM}$ only; ${ }^{* * *}$ Analysis excluded the 65 patients who had BM at initial presentation. 
Table 3: Analysis of factors affecting the time to brain metastases (TTBM)*

\begin{tabular}{|c|c|c|c|}
\hline Variable & No. & $\begin{array}{l}\text { Median TTBM } \\
\text { (months) }\end{array}$ & $p$ value \\
\hline \multicolumn{4}{|l|}{ Gender } \\
\hline Female & 9 & 5 & \multirow[t]{2}{*}{0.857} \\
\hline Male & 58 & 6 & \\
\hline \multicolumn{4}{|l|}{ Age } \\
\hline$<60$ & 42 & 6 & \multirow[t]{2}{*}{0.923} \\
\hline$\geq 60$ & 25 & 4 & \\
\hline \multicolumn{4}{|l|}{ Pathology } \\
\hline Adenocarcinoma & 29 & 6 & \multirow[t]{4}{*}{0.411} \\
\hline Squamous cell & 22 & 6 & \\
\hline Large cell & 10 & 5 & \\
\hline Undifferentiated & 6 & 6 & \\
\hline \multicolumn{4}{|c|}{ ECOG score at presentation } \\
\hline 1 & 14 & 7 & \multirow[t]{3}{*}{0.004} \\
\hline 2 & 31 & 6 & \\
\hline$\frac{2}{3}$ & 18 & $\frac{0}{4}$ & \\
\hline \multicolumn{4}{|l|}{ Stage } \\
\hline I-II & 18 & 8 & \multirow[t]{3}{*}{$<0.0001$} \\
\hline III & 33 & 5 & \\
\hline IV & 14 & 3 & \\
\hline \multicolumn{4}{|c|}{ Surgical resection of the $1^{\text {ry }}$} \\
\hline No & 57 & 6 & \multirow[t]{2}{*}{0.285} \\
\hline Yes & 10 & 7 & \\
\hline \multicolumn{4}{|c|}{ Chemotherapy received before BM diagnosis } \\
\hline No & 10 & 3 & \multirow[t]{2}{*}{$<0.0001$} \\
\hline Yes & 57 & 6 & \\
\hline \multicolumn{4}{|l|}{ Radiotherapy to the $1^{\text {ry }}$} \\
\hline No & 39 & 5 & \multirow[t]{2}{*}{0.434} \\
\hline Yes & 28 & 6 & \\
\hline
\end{tabular}

*Excluding patients who had brain metastases at initial presentation; ECOG: Eastern Cooperative Oncology Group

Table 4: Analysis of factors affecting overall survival (OS) after development of brain metastases (BM)

\begin{tabular}{|c|c|c|c|}
\hline Variable & No. & Median OS (months) & $p$ value \\
\hline \multicolumn{4}{|l|}{ Gender } \\
\hline Male & 116 & 6 & \multirow[t]{2}{*}{0.978} \\
\hline Female & 16 & 5 & \\
\hline \multicolumn{4}{|l|}{ Age (years) } \\
\hline$<60$ & 88 & 5 & \multirow[t]{2}{*}{0.781} \\
\hline$\geq 60$ & 44 & 5 & \\
\hline \multicolumn{4}{|l|}{ Pathology } \\
\hline Adenocarcinoma & 68 & 5 & \multirow[t]{4}{*}{0.604} \\
\hline Squamous cell & 34 & 6 & \\
\hline Large cell & 19 & 4 & \\
\hline Undifferentiated & 11 & Not reached & \\
\hline \multicolumn{4}{|c|}{ Status of the $1^{\text {ry }}$ at BM diagnosis ${ }^{*}$} \\
\hline Controlled & 36 & 8 & \multirow[t]{2}{*}{$<0.0001$} \\
\hline Uncontrolled & 31 & 3.5 & \\
\hline \multicolumn{4}{|l|}{ Coma } \\
\hline Yes & 20 & 4 & \multirow[t]{2}{*}{0.142} \\
\hline No & 99 & 5.5 & \\
\hline \multicolumn{4}{|c|}{ ECOG score at BM diagnosis } \\
\hline $1-2$ & 52 & 7 & \multirow{2}{*}{0.0001} \\
\hline $3-4$ & 46 & 3 & \\
\hline \multicolumn{4}{|l|}{ Extra-cranial metastases } \\
\hline Yes & 35 & 4 & \multirow{2}{*}{0.019} \\
\hline No & 97 & 6 & \\
\hline \multicolumn{4}{|l|}{ Number of BM } \\
\hline Single & 42 & 5 & \multirow[t]{2}{*}{0.776} \\
\hline Multiple & 90 & 5 & \\
\hline \multicolumn{4}{|l|}{ Metastatectomy $^{\text {** }}$} \\
\hline Yes & 11 & 6 & \multirow[t]{2}{*}{0.136} \\
\hline No & 31 & 4 & \\
\hline \multicolumn{4}{|c|}{ Chemotherapy after BM diagnosis } \\
\hline Yes & 47 & 7 & \multirow[t]{2}{*}{$<0.0001$} \\
\hline No & 85 & 4 & \\
\hline \multicolumn{4}{|l|}{ Whole brain irradiation } \\
\hline Yes & 129 & 5 & \multirow[t]{2}{*}{0.001} \\
\hline No & 3 & 2 & \\
\hline
\end{tabular}

*Analysis excluded 65 patients who presented initially with BM; ${ }^{* *}$ Including patients with single BM only; ECOG: Eastern Cooperative Oncology Group 


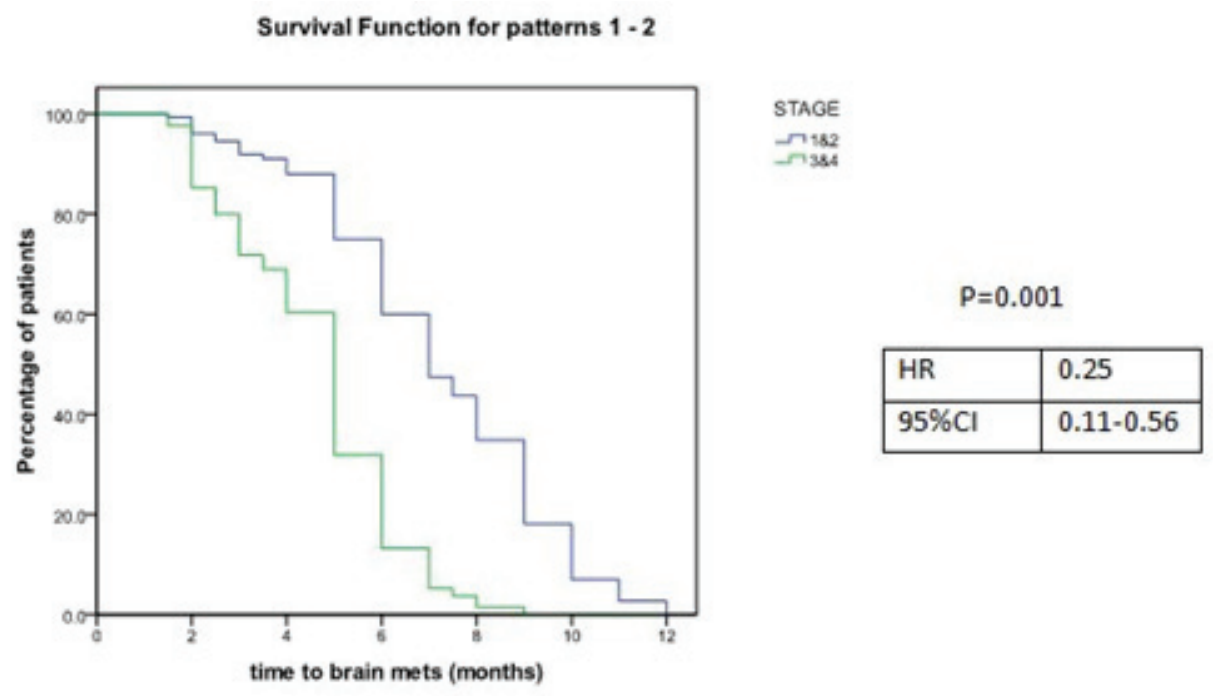

Figure 1: Cox regression analysis of time to development of brain metastases for patients with NSCLC according to stage group at presentation and its statistical significance.

\section{DISCUSSION}

Although this study is retrospective and included a specific group of NSCLC patients, yet it reflects most of the known features of this disease. The majority of patients were males $(87.9 \%)$ attributed to higher percentage of males smoking compared to females. The higher incidence of patients less than 60 years $(66.7 \%)$ should be an alarming finding. Early smoking and pollution are, likely, the major factors contributing to this finding.

Data from Western countries reveal that lung cancer is rarely diagnosed in people less than 35 years old. Incidence rates rise exponentially among patients older than 35 , then plateau, and begin to decline among patients of 80- 85 years old. NSCLC-incidence peaks among people at $65-85$ years $^{16}$.

About one third of the patients were non smokers (34.9\%), however, this cannot exclude the role of passive smoking. In addition to the symptoms attributed to the primary lesion in the lungs, the main symptoms of BM were headache $(41.7 \%)$, motor weakness $(30.7 \%)$ and vomiting (27.4\%). In a similar study, Nussbaum et al ${ }^{17}$ observed that only $10 \%$ of patients had symptomatic versus $40 \%$ in our study, denoting the late presentation of our patients and delay in performing CT or MRI.

The incidence of BM in patients with NSCLC is highly variable among different series. At the time of initial diagnosis $7 \%-10 \%$ of NSCLC-patients present with BM, and as many as $20 \%-40 \%$ develop BM at some point during their illness ${ }^{18,19}$, which is consistent with our results whereas 132/602 (22\%) patients had BM.

Forty two patients $(31.8 \%)$ had single BM; however CT scan was the diagnostic modality in nearly half of the patients $(47.7 \%)$. The frequency is expected to be less if MRI was routinely done at least in this group of patients. When CT scan was the only available diagnostic modality, about $50 \%$ of patients with BM were found to have a single lesion. However with emergence of MRI; about $20 \%$ of these patients were found to have multiple lesions ${ }^{20}$.

In agreement with the results obtained by Nussbaum et $\mathrm{al}^{17}$, approximately $85 \%$ of our patients presented with metastases in the cerebral hemispheres and $19.3 \%$ had cerebellar metastases and only $1.6 \%$ had brain stem metastases.

In our study; the median TTBM for the whole group ranged from 2 to 22 months with a median of 6 months. The early stage at presentation was an independent factor influencing TTBM. Noteworthy, patients with stage I-II had median TTBM of 8 months versus 5 months in patients with stage III, and only 3 months only in patients with stage IV $(P=0.001)$. Which are comparable to the obtained by Theodore et al.21; as the median TTBM was 9.3 months and stage IIIB patients had a significantly higher 2-year actuarial incidence of BM when compared to stage II/IIIA (36\% vs. $29 \%, p<.04)^{21}$.

Whole brain irradiation was the main modality of treatment in our group of patients. Besides, metastatectomy was performed in highly selected cases (11 cases), who had solitary metastases in the brain without metastases in other sites.

The median progression free survival was 4.5 months which is close to the OS after development of BM (5 months) attributed to the fact that progression is usually followed by death. While in a similar study of patients with BM from NSCLC, the median OS for the entire patient population was 7.8 months. After the 
diagnosis of BM, OS was similar for both, the group of patients with $\mathrm{BM}$ at initial diagnosis and the other group who developed BM later (5 months vs. 4 months, $\mathrm{p}=$ 0.53)22. Taking into consideration that our patients', progression free survival and OS were calculated from time of development of BM, subsequently our outcomes are fairly acceptable.

Various prognostic models have been developed for patients with BM to identify those with favorable outcome 23- $25^{\text {. }}$.

In our study; the median survival in patients with good performance status (ECOG 1-2) was 7 months, while in those with poor performance status (ECOG $3-4)$ it was only 3 months $(P<0.0001)$. Patients with extracranial metastases had median OS of 4 months versus 6 months in patients with $\mathrm{BM}$ only $(p=0.019)$. In context, Gasper et al reviewed data of 1200 patients with BM obtained after three RTOG trials. They were classified into three classes with significantly different survival. The best survival was 7.1 months observed in patients $<65$ years of age with a Karnofsky Performance Status (KPS) of at least 70, and a controlled primary tumor with the brain the only site of metastases. While, the worst survival was 2.3 months reported in patients with a KPS less than 70 . All other patients had relatively minor differences in observed survival, with a median of 4.2 months $^{26}$.

In the current work, multivariate analysis revealed that the status of the lung primary and administration of chemotherapy after development of BM are independent prognostic factors affecting OS.

The availability of recent diagnostic modalities would be a promise to diagnose a higher percentage of patients with BM while being asymptomatic. Aggressive local therapy (e.g. surgery or stereotactic RT) can be offered to a selected group of these patients who may have a favourable prognosis.

\section{CONCLUSION}

Patients with stage I-II NSCLC had significantly longer TTBM than those with stage III-IV. After development of BM; patients with good performance status (ECOG 1-2), no extracranial metastases and controlled lung primary have significantly longer OS. Chemotherapy and WBI may prolong OS in such group of patients.

\section{REFERENCES}

1. American Cancer Society. Cancer Facts \& Figures 2016. Atlanta: American Cancer Society; 2016. Available from: https://www.cancer.org/research/cancer-facts-statistics/ all-cancer-facts-figures/cancer-facts-figures-2016.html
2. Ferlay J, Shin HR, Bray F, et al (2010). GLOBOCAN 2008, Cancer Incidence and Mortality Worldwide: IARC CancerBase No. 10 [Internet]. Lyon, France: International Agency for Research on Cancer; 2010. Available from: http://globocan.iarc.fr.

3. Salim EI, Jazieh AR, Moore MA. Lung cancer incidence in the arab league countries: risk factors and control. Asian Pac J Cancer Prev. 2011; 12(1): 17-34.

4. Langer CJ, Mehta MP. Current management of BM, with a focus on systemic options. J Clin Oncol. 2005; 23(25): 6207-6219.

5. Sawaya R, Bindal RK, Lang FF, et al. Metastatic brain tumors. In: Kaye AH, Laws ER (eds): Brain Tumors. London: Churchill Livingstone; 2001: 999-1026.

6. Lassman AB, DeAngelis LM. BM. Neurol Clin. 2003; 21(1):1-23.

7. Johnson JD, Young B. Demographics of BM. Neurosurg Clin N Am. 1996 ;7(3): 337-344.

8. Chen AM, Jahan TM, Jablons DM, Garcia J, Larson DA. Risk of cerebral metastases and neurological death after pathological complete response to neoadjuvant therapy for locally advanced non small cell lung cancer: Clinical implications for the subsequent management of the brain. Cancer. 2007; 109(8):1668-1675.

9. Vecht CJ, Haaxma-Reiche H, Noordijk EM, et al. Treatment of single BM: radiotherapy alone or combined with neurosurgery? Ann Neurol. 1993; 33(6):583-590.

10. Al-Shamy G, Sawaya R. Management of BM: the indispensable role of surgery. J Neurooncol. 2009; 92(3): 275-282.

11. Bernardo G, Cuzzoni Q, Strada MR, et al. First-line chemotherapy with vinorelbine, gemcitabine, and carboplatin in the treatment of BM from non-small-cell lung cancer: a phase ii study. Cancer Invest. 2002; 20(3): 293-302.

12. Robinet G, Thomas P, Breton JL, et al. Results of a phase iii study of early versus delayed whole brain radiotherapy with concurrent cisplatin and vinorelbine combination in inoperable BM of non-small cell lung cancer: Groupe Francais de Pneumo-Cancerologie (gfpc) protocol 95-1. Ann Oncol. 2001; 12(1):59-67.

13. Bradbury PA, Twumasi-Ankrah P, Ding K, et al. The impact of BM on OS (OS) in National Cancer Institute of Canada Clinical Trials Group (NCIC CTG) clinical trials (CT) in advanced non-small cell lung cancer (NSCLC). J Clin Oncol 2009; 27(15S): 8075.

14. Olson JJ, Paleologos NA, Gaspar LE, et al. The role of emerging and investigational therapies for metastatic brain tumors: a systematic review and evidence-based clinical practice guideline of selected topics. J Neurooncol. 2010; 96(1): 115-142.

15. Improta G, Zupa A, Fillmore H, et al. Protein pathway activation mapping of BM from lung and breast cancers reveals organ type specific drug target activation. J Proteome Res. 2011; 10(7): 3089-3097. 
16. Jemal A, Murray T, Ward E, et al. Cancer statistics, 2005. CA Cancer J Clin. 2005; 55(1): 10-30.

17. Nussbaum ES, Djalilian HR, Cho KH, Hall WA. BM. Histology, multiplicity, surgery and survival. Cancer. 1996; 78(8): 1781-1788.

18. Robinet G, Barlesi F, Gervais R, et al. Pemetrexed and cisplatin as first-line chemotherapy for advanced non-small cell lung cancer (NSCLC) with measurable asymptomatic inoperable BM (BM): A multicenter phase ii trial (GFPC 07-01). J Clin Oncol. 2010; 28(15_suppl): 7595.

19. Louie AV, Rodrigues G, Yaremko B, et al. Management and prognosis in synchronous solitary resected BM from non-small cell lung cancer. Clin Lung Cancer. 2009; 10(3): 174-179.

20. Schellinger PD, Meinck HM, Thron A. Diagnostic accuracy of MRI compared to CT in patients with BM. J Neurooncol. 1999; 44(3): 275-281.

21. Robnett TJ, Machtay M, Stevenson JP, Algazy KM, Hahn SM. Factors affecting the risk of BM after definitive chemoradiation for locally advanced non-small-cell lung carcinoma. J Clin Oncol. 2001; 19(5): 1344-1349.
22. Ali A. Goffin JR, Arnold A, Ellis PM. Survival of patients with non-small-cell lung cancer after a diagnosis of BM; Curr Oncol. 2013; 20(4): e300-306.

23. Weltman E, Salvajoli JV, Brandt RA, et al. Radiosurgery for BM: a score index for predicting prognosis. Int J Radiat Oncol Biol Phys. 2000; 46(5): 1155-1161.

24. Lorenzoni J, Devriendt D, Massager N, et al. Radiosurgery for treatment of BM: estimation of patient eligibility using three stratification systems. Int J Radiat Oncol Biol Phys. 2004; 60(1): 218-224.

25. Golden DW, Lamborn KR, McDermott MW, et al. Prognostic factors and grading systems for OS in patients treated with radiosurgery for BM: variation by primary site. J Neurosurg. 2008; 109 (suppl): 77-86.

26. Gaspar L, Scott C, Rotman M, et al. Recursive partitioning analysis (rpa) of prognostic factors in three Radiation Therapy Oncology Group (rtog) BM trials. Int J Radiat Oncol Biol Phys. 1997; 37(4): 745-751. 